\title{
Graft flow assessment using a transit time flow meter in fractional flow reserve-guided coronary artery bypass surgery
}

\author{
Kentaro Honda, MD, ${ }^{a}$ Yoshitaka Okamura, $\mathrm{MD}, \mathrm{PhD},{ }^{\mathrm{a}}$ Yoshiharu Nishimura, $\mathrm{MD}, \mathrm{PhD},{ }^{\mathrm{a}}$ \\ Shunji Uchita, MD, PhD, ${ }^{a}$ Mitsuru Yuzaki, MD, ${ }^{a}$ Masahiro Kaneko, MD, ${ }^{a}$ Nobuko Yamamoto, MD, \\ Takashi Kubo, MD, $\mathrm{PhD}{ }^{\mathrm{b}}$ and Takashi Akasaka, $\mathrm{MD}, \mathrm{PhD}^{\mathrm{b}}$
}

\begin{abstract}
Objective: To evaluate the relationship between preoperative severity of coronary stenosis occurring with fractional flow reserve (FFR), and the intraoperative bypass graft flow pattern.
\end{abstract}

Methods: In all, 72 patients were enrolled in this retrospective study. The FFR value of the left anterior descending artery was evaluated, and data on "in situ" bypass grafting from the internal thoracic artery to the left anterior descending artery were assessed. Patients were divided into 3 groups according to preoperative FFR values (Group S: FFR $<0.70$; group M: $0.70 \leq$ FFR $<0.75$; and group $\mathrm{N}$ : FFR $\geq 0.75)$.

Results: In groups $\mathrm{S}, \mathrm{M}$, and N, respectively, mean graft flow was $24.7 \pm 10.6 \mathrm{~mL} /$ minute, $19.2 \pm 14.0 \mathrm{~mL} / \mathrm{minute}$, and $16.0 \pm 9.7 \mathrm{mLmL} /$ minute; pulsatility index was $2.35 \pm 0.6,3.02 \pm 1.1$, and 5.51 \pm 8.20 ; and number of patients with systolic reverse flow was $3(6.8 \%), 5(35.7 \%)$, and $4(28.6 \%)$. Significant differences were observed in graft flow $(P=.009)$, pulsatility index $(P=.038)$, and proportion of systolic reverse flow $(P=.023)$ among the 3 groups. In all patients, graft patency was confirmed with intraoperative fluorescence imaging; postoperative graft patency was confirmed with multislice computed tomography or coronary angiography in 69 patients (follow-up interval: 213 days). Early graft failure occurred in 1 patient.

Conclusions: As coronary stenosis severity increased, graft flow increased, pulsatility index decreased, and proportion of patients with systolic reverse flow increased. In mild coronary artery stenosis, the chance of flow competition between the native coronary artery and the bypass graft increased. ( $\mathrm{J}$ Thorac Cardiovasc Surg 2015;149:1622-8)

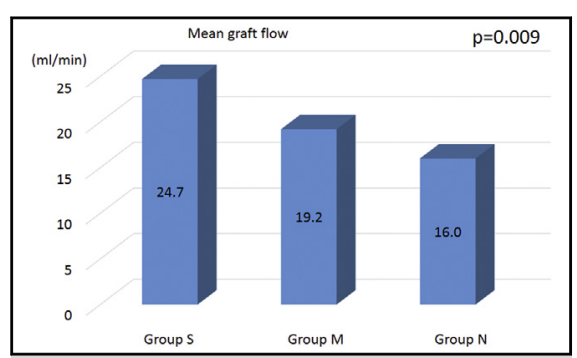

Graft flow increased with the severity of coronary stenosis.

\section{Central Message}

Flow competition between coronary artery and bypass graft may occur in mild coronary artery stenosis. Not only the anatomic evaluation of coronary stenosis but also the functional assessment using fractional flow reserve should 1 be considered.

\section{Perspective}

These findings are important in coronary artery bypass surgery to achieve an effective bypass grafting. "In situ" internal thoracic artery graft was considered to be useful in mild coronary stenosis as it could act as a viable graft with long-term no-flow patency. In this study, graft flow assessment was limited to "in situ" internal thoracic artery to left anterior descending artery graft. It is necessary to evaluate in other graft and other coronary territory in a diverse coronary patients in the future.

See Editorial Commentary page 1629.
Coronary artery bypass surgery is a well-established procedure for patients with myocardial ischemia. For coronary surgery, target coronary arteries are selected mainly according to anatomic, as opposed to functional,

\footnotetext{
From the Departments of Thoracic and Cardiovascular Surgery ${ }^{\mathrm{a}}$ and Cardiovascular Medicine, ${ }^{\text {b }}$ Wakayama Medical University, Wakayama, Japan.

Received for publication Jan 3, 2015; revisions received Feb 7, 2015; accepted for publication Feb 20, 2015; available ahead of print April 1, 2015.

Address for reprints: Kentaro Honda, MD, Department of Thoracic and Cardiovascular Surgery, 811-1 Kimiidera, Wakayama, 641-0012 Japan (E-mail: honda-k@wakayama-med.ac.jp).

$0022-5223 / \$ 36.00$

Copyright (c) 2015 by The American Association for Thoracic Surgery

http://dx.doi.org/10.1016/j.jtcvs.2015.02.050
}

severity of the stenosis. However, the purpose of coronary revascularization is to improve myocardial ischemia; therefore, the functional aspects of myocardial ischemia should be considered.

Recent reports have revealed that percutaneous coronary intervention based on functional evaluation via a measure of fractional flow reserve (FFR) achieves excellent results. In the FAME (FFR Versus Angiography for Multivessel Evaluation) study, ${ }^{1}$ FFR-guided percutaneous coronary intervention significantly reduced the rate of mortality and myocardial infarction for lesions, at 2 years, but only if the FFR was $\leq 0.80$. In addition, the 5-year results of the DEFER (for deferral of percutaneous coronary intervention) study ${ }^{2}$ indicated that outcomes were excellent after 


\section{Abbreviations and Acronyms \\ FFR = fractional flow reserve \\ ITA $=$ internal thoracic artery \\ LAD $=$ left anterior descending \\ MSCT $=$ multislice computed tomography \\ $\mathrm{TTFM}=$ transit time flow meter}

deferred percutaneous coronary intervention of an intermediate coronary stenosis (defined as a lesion with an FFR $\geq 0.75) .^{2}$ These results indicate that functional evaluation may lead to desirable results in coronary revascularization. Recently, an effort was undertaken to introduce FFR-guided revascularization into cardiac surgery, ${ }^{3}$ but the question of whether a cutoff value of 0.75 in FFR is adequate for coronary surgery has not been addressed. Botman and colleagues ${ }^{3}$ reported that the incidence of graft occlusion 1 year after surgery was $>10 \%$ in patients with FFR values of $\geq 0.70$.

The efficacy of coronary artery bypass grafting, unlike percutaneous coronary intervention, relies on the bypass graft flow dominating the native coronary flow. To be an efficient bypass, the graft flow must exceed the native coronary flow. This study was designed to assess the efficacy of FFR evaluation in coronary artery bypass grafting, via evaluation of the relationship between the preoperative severity of the coronary artery stenosis, as assessed by FFR, and the intraoperative graft flow and graft flow pattern.

\section{METHODS}

\section{Patient Groups}

A total of 72 patients who were eligible for coronary artery bypass grafting were enrolled in this retrospective study. Patients underwent coronary angiography and FFR-based functional evaluation of mild-to-moderate stenosis of the left anterior descending (LAD) artery. Patients were divided into 3 groups, according to their preoperative FFR value. Group S (FFR $<0.70$ ) had the most-severe coronary stenosis; Group $\mathrm{M}(0.70 \leq$ FFR $<0.75)$ had mild stenosis; and Group N (FFR $\geq 0.75)$ had functionally nonstenotic lesions.

In situ internal thoracic artery (ITA)-to-LAD artery bypass was performed. Mean graft flow, pulsatility index, diastolic filling, and systolic reverse flow were evaluated, using a transit time flow meter (TTFM), for each group during surgery. In addition, the patency of the bypass graft was assessed postoperatively. Patient characteristics are shown in Table 1.

\section{Fractional Flow Reserve Measurement}

Measurements of FFR were made only in cases of mild-to-moderate lesions, in which determination of whether significant stenosis is present in patients undergoing coronary angiography is difficult. Measurement of FFR was not performed in cases of severe coronary stenosis.

Intracoronary pressure was measured using a 0.014 -inch pressure guide-wire (PressureWire Aeris, St Jude Medical, Inc, St Paul, Minn). First, the proximal coronary pressure was recorded by the guiding catheter. Calculation of FFR was made as the mean distal coronary pressure divided by the mean aortic pressure during maximal hyperemia.
Maximal hyperemia was induced ${ }^{4,5}$ by the intravenous continuous infusion of adenosine $5^{\prime}$-triphosphate (ATP) administered at 150 to $180 \mu \mathrm{g} / \mathrm{kg} /$ minute.

\section{Surgical Strategy}

Revascularization of the coronary artery was performed with or without cardiopulmonary bypass. An in situ ITA (both right and left ITA) was used as a bypass graft to the LAD artery area. No Y or T grafts were used in this study.

\section{Intraoperative Graft Flow Measurement}

Intraoperative graft flow measurement was performed using a TTFM (VeriQ System, Medistim, Oslo, Norway). The usefulness of graft flow measurement is mentioned in the ESC-EACTS (European Society of Cardiology and European Association for Cardio-Thoracic Surgery) guidelines. ${ }^{6}$ Graft flow measurements were performed just before chest closure and after hemodynamic stabilization. The parameters evaluated with use of the TTFM were mean bypass graft flow, pulsatility index, diastolic filling, and systolic reverse flow. ${ }^{7-9}$

Mean bypass graft flow. Mean graft flow is expressed in $\mathrm{mL} / \mathrm{minute}$ and is useful for indicating how a bypass is flowing. But it is a poor indicator of the quality of the anastomosis, because the index is influenced by many variables, such as systolic blood pressure, vascular resistance, graft quality, coronary microvascular resistance, and anastomotic quality. Several articles regarding intraoperative bypass graft flow have been published; a mean graft flow of $>20 \mathrm{~mL} /$ minute is considered a good graft. ${ }^{7-10}$

Pulsatility index. The pulsatility index is expressed as an absolute value and is considered to be a good indicator of the anastomotic flow pattern, and consequently, of anastomotic quality. This value is obtained by dividing the numeric difference between the maximum flow and the minimum flow by the mean flow: Pulsatility index $=$ (maximal flow - minimum flow / mean flow). The index should range from 1 to 5 in a good graft $^{6}$; an index $<3.0$ is an adequate value for a good graft. ${ }^{9,10}$ The adequate and backward flow patterns by the TTFM measurements are shown in Figure 1.

Diastolic filling. Diastolic filling indicates the proportion of diastolic graft flow during the entire graft flow. Because coronary artery flow physiologically occurs during diastole, diastolic filling in a proper graft should range from $45 \%$ to $80 \%$. Diastolic filling of $<25 \%$ is considered to an inadequate graft. ${ }^{9}$

Systolic reverse flow. Reverse, or backward, flow during the systolic phase indicates flow competition between the bypass graft and the native coronary artery. Backward flow indicates that the flow through the graft is directed backward across the anastomotic site. Reverse flow is measured as the percentage of the area below the zero line, compared with the total flow area. A backward flow value of $\geq 3.0 \%$ can be considered a cutoff value that predicts early graft failure.

\section{Intraoperative Graft Imaging}

In all patients, intraoperative fluorescence graft imaging was performed. The Photodynamic Eye (PDE; Hamamatsu Photonics K.K., Shizuoka, Japan) was used in our institution. This system is based on the fluorescence of indocyanine green when it is illuminated by laser energy. After intravenous injection of indocyanine green, fluorescence generated in the blood is captured by a camera, and the vessels are visualized. The usefulness of intraoperative fluorescence imaging for coronary surgery has been reported elsewhere. ${ }^{11-13}$

\section{Intraoperative Graft Revision}

Graft revision was considered when both TTFM and fluorescence imaging assessment indicated improper results. In patients with a high pulsatility index, with no flow, as indicated by fluorescence imaging, graft revision was considered. If the graft flow was confirmed in the anastomotic 
TABLE 1. Preoperative patient characteristics

\begin{tabular}{lc}
\hline \multicolumn{1}{c}{ Characteristic } & Value \\
\hline Male:female ratio (n) & $56: 16$ \\
Age (y) & $68.4 \pm 9.3$ \\
Hypertension & $66(91.7)$ \\
Dyslipidemia & $58(80.6)$ \\
Diabetes mellitus & $42(58.3)$ \\
$\quad$ Insulin & $20(27.8)$ \\
Anterior myocardial infarction & \\
$\quad$ Acute/old & $2 / 22$ \\
Angina pectoris & 48 \\
Coronary lesion & \\
$\quad$ Single vessel disease & 6 \\
$\quad$ Double vessel disease & 10 \\
Triple vessel disease & 46 \\
Left main trunk & 10 \\
Ejection fraction $(\%)$ & $54.5 \pm 11.2$ \\
\hline Values are $\mathrm{n}(\%), \mathrm{n}$, or mean \pm SD, unless otherwise indicated
\end{tabular}

Values are $\mathrm{n}(\%), \mathrm{n}$, or mean $\pm \mathrm{SD}$, unless otherwise indicated.

site, via fluorescence imaging, and the patient had a high pulsatility index, without any technical trouble, then flow competition was thought to be the likely cause of difficulty, and the option of graft revision was not considered.

\section{Postoperative Graft Evaluation}

Postoperative graft evaluations were performed. Cardiac imaging with multislice computed tomography (MSCT) was used in patients without chronic kidney disease, and plane magnetic resonance imaging was used in patients who had chronic kidney disease. In some cases, coronary angiography was performed. In MSCT and magnetic resonance imaging examinations, a $\beta$-blocker and isosorbide mononitrate were used, to ensure adequacy of the images. Postoperative graft evaluation was performed, in patients with and without symptoms, within 1 year of surgery.

\section{Statistical Analysis}

Statistical analyses were performed using SPSS software, Version 20 (SPSS Inc, Chicago, Ill). Continuous data are presented as mean \pm SD. Variables with a normal distribution were compared using paired and unpaired $t$ tests. Between-group differences, and data that are not homogeneously distributed, were tested using Kruskal-Wallis analysis of variance. The clinical characteristics of the groups were compared using $\chi^{2}$ analysis. To evaluate the correlation between preoperative FFR and intraoperative mean graft flow, analysis using the Spearman correlation coefficient was conducted.

\section{RESULTS}

The 72 patients were divided into 3 groups, according to the preoperative FFR measurements of the LAD artery. A total of 44 patients were included in group $\mathrm{S}$ $($ FFR $<0.70), 14$ patients in group $\mathrm{M}(0.70 \leq$ FFR $<0.75$ ), and 14 patients in group $\mathrm{N}$ (FFR $\geq 0.75$ ).

For LAD artery revascularization, left ITA was used in 58 patients and right ITA in 14 patients. An off-pump coronary artery bypass was performed in 51 patients; coronary artery bypass grafting was performed in 21 patients. Concomitant surgery was performed in 9 patients. No hospital deaths or major adverse cardiac events occurred. Details of the procedures are shown in Table 2. Graft revisions based on the results of indocyanine green angiography were not performed.

\section{Transit Time Flow Meter Measurement}

The mean graft flow in groups $\mathrm{S}, \mathrm{M}$, and $\mathrm{N}$, respectively, was $24.7 \pm 10.6 \mathrm{~mL} /$ minute (range: $11.0-54.0 \mathrm{~mL} /$ minute), $19.2 \pm 14.0 \mathrm{~mL} / \mathrm{minute}$ (range: $6.0-53.0 \mathrm{~mL} /$ minute) and $16.0 \pm 9.7 \mathrm{~mL} /$ minute (range: $1.0-35.0 \mathrm{~mL} /$ minute).

\section{good pattern}

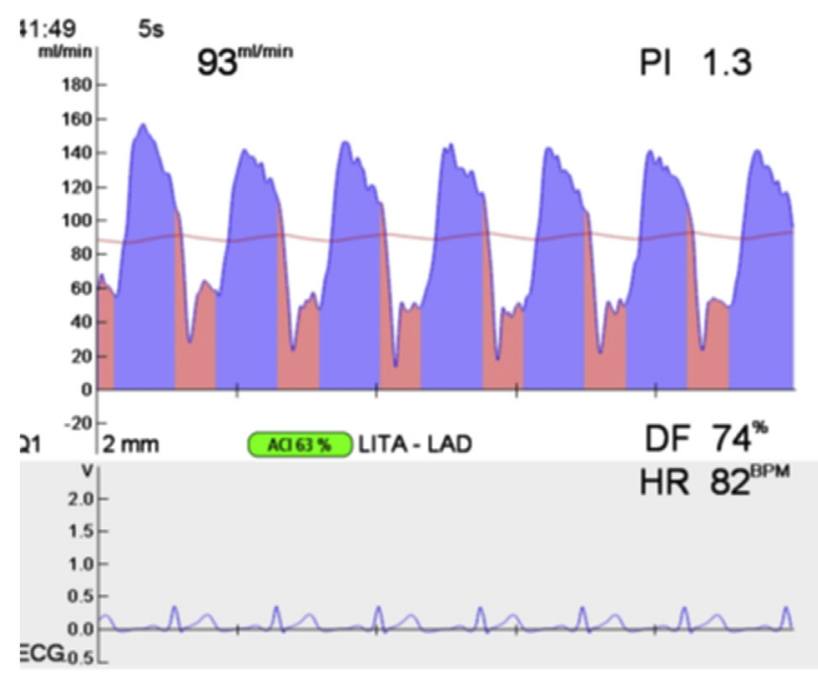

\section{flow competition}

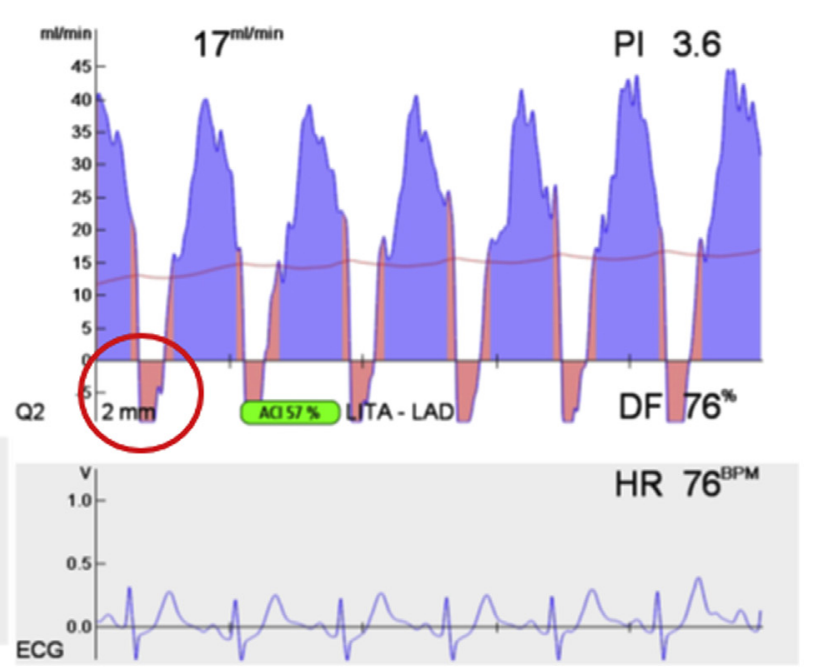

FIGURE 1. Good pattern and systolic reverse flow (= flow competition) pattern of bypass grafts, indicated by transit time flow meter measurements. $P I$, Pulsatility index; $A C I$, acoustic coupling index; LITA, left internal thoracic artery; $L A D$, left anterior descending artery; $D F$, diastolic filling; $H R$, heart rate; $B P M$, beats per minute; $E C G$, echocardiogram. 
TABLE 2. Operative data

\begin{tabular}{lc}
\hline \multicolumn{1}{c}{ Procedure } & n \\
\hline Off-pump coronary artery bypass & 51 \\
Coronary artery bypass grafting & 21 \\
LAD revascularization & \\
$\quad$ Right internal thoracic artery & 14 \\
$\quad$ Left internal thoracic artery & 58 \\
Distal anastomosis (mean $\pm \mathrm{SD})$ & $2.7 \pm 1.06$ \\
Concomitant surgery: AVR $(\mathrm{n}=3) ; \operatorname{MVP}(\mathrm{n}=2) ;$ & 8 \\
$\quad$ LVR $(\mathrm{n}=1) ;$ TAR $(\mathrm{n}=1) ;$ ASD closure $(\mathrm{n}=1)$ & \\
\hline
\end{tabular}

$L A D$, Left anterior descending artery; $A V R$, aortic valve replacement; $M V P$, mitral valve plasty; $L V R$, left ventricular restoration; TAR, total arch replacement; $A S D$, atrial septal defect; $S D$, standard deviation.

Significant differences were observed among the 3 groups $(P=.009)$. The pulsatility index in groups $\mathrm{S}, \mathrm{M}$, and $\mathrm{N}$, respectively, was $2.35 \pm 0.6$ (range: 0.8- 4.6), $3.02 \pm 1.1$ (range: 1.8-5.0), and 5.51 \pm 8.20 (range: 1.7-32.9). Significant differences were observed among the 3 groups $(P=.038)$. Patients with a pulsatility index of $\geq 3.0$ in groups $\mathrm{S}, \mathrm{M}$, and $\mathrm{N}$, respectively, numbered $10(23.2 \%)$, $5(35.7 \%)$, and $6(42.9 \%)(P=.310$; Figures 2 and 3$)$.

Diastolic filtration in groups $\mathrm{S}, \mathrm{M}$, and $\mathrm{N}$, respectively, was $71.6 \pm 8.10 \%$ (range: $48-83 \%$ ), $72.0 \pm 9.1 \%$ (range: $53-84 \%$ ) and $66.9 \pm 18.3 \%$ (range: $49-80 \%$ ); no significant differences were observed among the 3 groups $(P=.812)$. In addition, systolic reverse flow, which indicates flow competition between native coronary flow and bypass graft flow, was evaluated. The number of patients with systolic reverse flow in groups $\mathrm{S}, \mathrm{M}$, and $\mathrm{N}$, respectively, was $3(6.8 \%), 5(35.7 \%)$, and $4(28.6 \%)$. A significant difference was observed among groups $(P=.023$; Figure 4).In all patients, blood flow through the anastomotic site was confirmed, via intraoperative graft imaging using indocyanine green angiography.

\section{Patency}

The patency of the graft was evaluated in 69 patients (follow-up interval: 213 days).

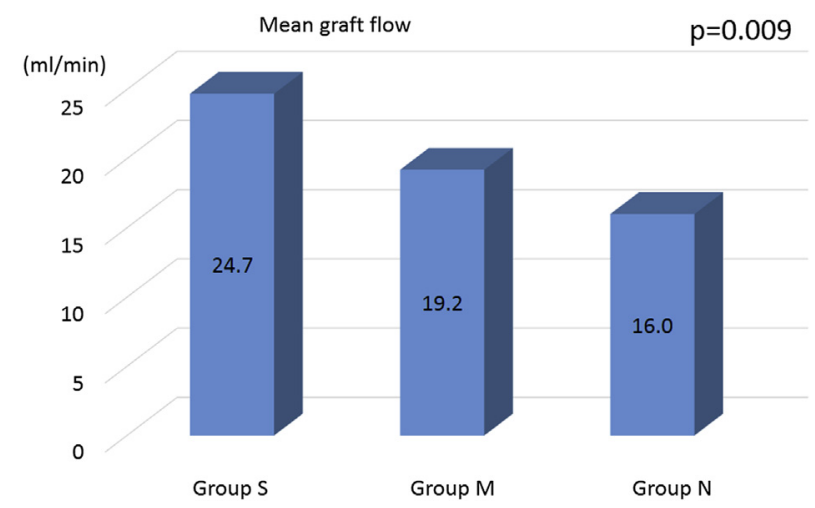

FIGURE 2. The graph shows how the graft flow (shown as means for each group) increased with the severity of the coronary stenosis.
Multislice computed tomography was used in 65 patients, magnetic resonance imaging in 2, and coronary angiography in 2 patients. A distal thread sign at the ITA graft was observed in $2(4.2 \%), 3(21 \%)$, and $6(50 \%)$ patients in groups $\mathrm{S}, \mathrm{M}$, and $\mathrm{N}$, respectively. A significant difference was observed among the 3 groups $(P=.002)$.

Early graft failure was observed in 1 patient in group $S$. In this patient, intraoperative mean graft flow was $20 \mathrm{~mL} / \mathrm{minute}$, and the pulsatility index was 2.0. No systolic reverse flow was observed. The reason for the graft occlusion in this patient was unknown, and repeat off-pump coronary artery bypass was performed 10 months after the operation.

Midterm mortality was observed in 2 patients (follow-up period: 953 days). One died from gastric cancer, the other from a cardiac event. In the latter patient, emergent coronary angiography was performed on admission, and no graft troubles were found. Arrhythmia was considered to be the cause of death.

\section{DISCUSSION}

The need for coronary revascularization is determined by insufficient coronary artery flow. In coronary artery bypass grafting, unlike percutaneous coronary intervention, graft flow needs to exceed native coronary flow to create an effective bypass. If the stenosis of the native coronary artery is not very severe, surgeons have to consider the competition between the coronary flow and the bypass flow.

We assessed this difference using intraoperative fluorescence imaging of the graft. Enhancement of the blood flow initially started from the ITA graft and spread to the native coronary artery. However, in cases with competitive flow, intraoperative fluorescence imaging showed that blood flow enhancement started from the native coronary flow and spread to the ITA graft in a retrograde fashion, through the anastomotic site. Competitive flow should be considered in cases of mild coronary stenosis.

In this study, we considered the anatomic degree of coronary stenosis as well as the functional degree of myocardial ischemia using FFR. In addition, we assessed the relationship between preoperative FFR values and the intraoperative bypass graft pattern. To unify the bypass graft flow, an "in situ" ITA-to-LAD artery bypass graft was selected; no aortocoronary bypasses were performed. As coronary stenosis becomes more severe, the mean bypass graft flow increases, indicating that in severe coronary lesions, bypass graft flow is likely to exceed the native coronary flow. The mean bypass graft flow exceeded $20 \mathrm{~mL} / \mathrm{minute}$ only in group $\mathrm{S}$; this level of flow was considered adequate.

The pulsatility index is an indicator of graft quality that decreases with the severity of the coronary stenosis. Low values of this index indicate an adequate bypass; high 


\section{Pulsatility Index}

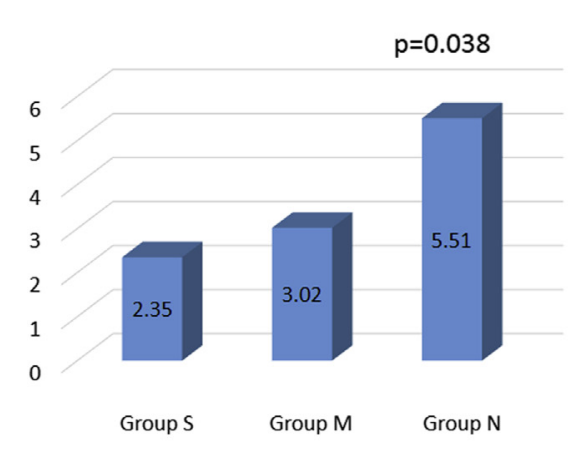

Proportion of $\mathrm{PI}>3.0$

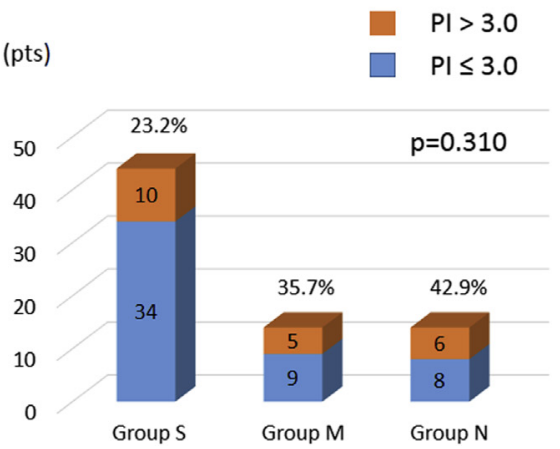

FIGURE 3. The pulsatility index decreased with the severity of the coronary stenosis $(l e f t)$. In group $S$, the proportion of patients with a PI $>3.0$ was smaller than the proportions in the other groups (right). PI, Pulsatility index; pts, patients.

values indicate technical failure and flow competition with the bypass graft. Low values were observed in the group who had severe coronary stenosis; high values were observed in the group who had mild coronary stenosis. These findings indicate that graft flow competition occurred in the group who had mild coronary stenosis, because technical failure had been prevented by intraoperative fluorescence imaging.

Several articles have debated the significance of TTFM measurements, such as mean graft flow and pulsatility index, but fewer articles have addressed systolic reverse flow. Di Giammarco and colleagues, ${ }^{9}$ using a measure of systolic reverse flow, demonstrated flow competition between native coronary flow and bypass graft flow. We found that the incidence of "graft flow completion," as indicated by systolic reverse flow was higher, based on FFR measurements, in mild, versus moderate or severe, coronary stenosis.
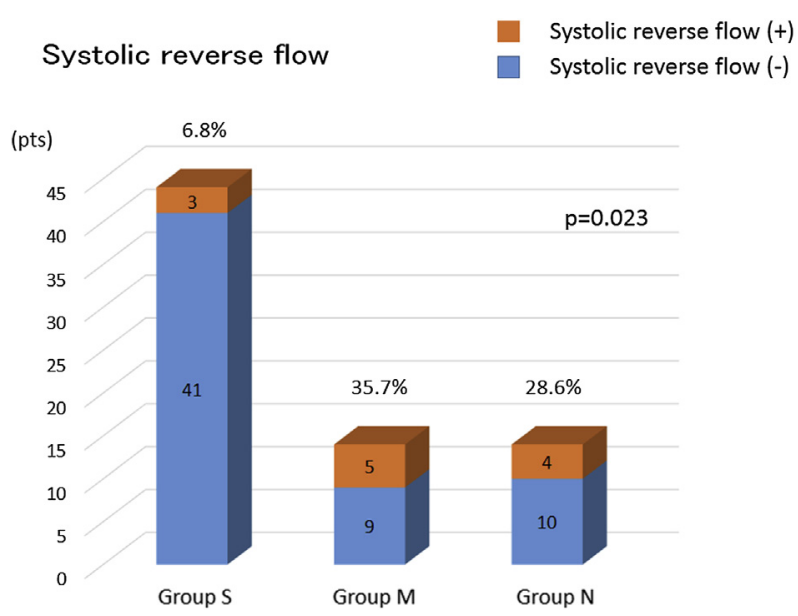

FIGURE 4. The proportion of patients with systolic reverse flow in group $\mathrm{S}$ was smaller than that in the other groups. A statistically significant difference was observed. pts, Patients.
In some patients in groups $\mathrm{M}$ and $\mathrm{N}$, postoperative graft assessment revealed a distal thread sign at the ITA graft, which indicates nonfunctional bypass grafting. In some cases, graft flow evaluation with echocardiography was performed, which revealed low diastolic flow. These results suggested the possibility of graft flow competition in mild coronary stenosis.

In these situations, use of an in situ ITA graft was considered to be the best choice, as Kitamura and colleagues ${ }^{14}$ reported that an ITA graft can act as a viable graft with long-term no-flow patency. Using an in situ ITA graft in patients with mild stenosis can turn a nonfunctional graft into a functional graft after progression of the native coronary artery. Because the ITA graft is a living graft, it may be the best choice for patients with mild coronary stenosis.

We confirmed this phenomenon in 2 patients in group $\mathrm{N}$ and 1 patient in group $\mathrm{S}$. One patient in group $\mathrm{N}$ was a 73-year-old woman whose coronary angiography indicated significant $(75 \%)$ stenosis in the LAD artery. In this patient, the coronary lesions were anatomically diagnosed as severe, and preoperative FFR was 0.81 in the LAD artery. Bypass from the left ITA to the LAD artery was performed, and intraoperative TTFM indicated a mean bypass flow of $21 \mathrm{~mL} /$ minute, a high pulsatility index of 2.4 , and diastolic filling of $78 \%$. Systolic reverse flow was not observed.

A graft string sign was observed at the short-term evaluation (43 days after surgery) in the MSCT. Measurements with the TTFM revealed that flow competition was the likely reason for the string sign. Four years after the operation, reevaluation of the bypass graft with MSCT showed improvement of the graft string sign and progression of the native coronary stenosis.

The other patient was a 75-year-old man in group S. Preoperative coronary angiography revealed $75 \%$ stenosis in the LAD artery and a decreased FFR value of 0.68 . The TTFM measurements indicated a decreased mean graft flow of $12 \mathrm{~mL} /$ minute and an adequate pulsatility index of 

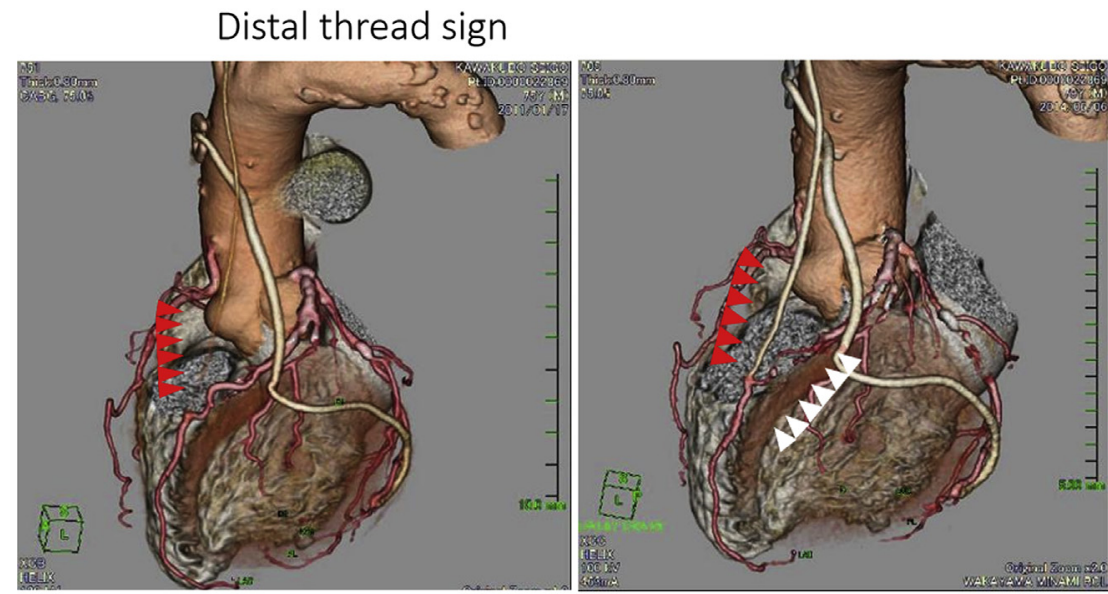

Distal thread sign of LITA to LAD graft

Improvement of graft enhancement (red arrows) (red arrows)

and progression of native coronary stenosis

(white arrows)

FIGURE 5. A distal thread sign was observed in a LITA-to-LAD bypass graft at 83 days after the operation. Progression of the native coronary stenosis and improvement of the LITA flow were observed at 3 years after the operation. LITA, Left internal thoracic artery; LAD, left anterior descending artery.

2.4. Diastolic filling was $73 \%$, and systolic reverse flow was not observed. Multislice CT of the left ITA graft 83 days after surgery revealed a distal thread sign. However, 3 years postoperatively, the ITA graft was clearly observed, as was progression of the native coronary artery stenosis (Figure 5). These results indicate that ITA flow increased with the progression of native coronary stenosis.

\section{Limitations}

This study has some limitations. First, given that the study is retrospective, the possibility of bias cannot be excluded. Second, currently, patients who undergo coronary bypass surgery have multiple coronary lesions and require multiple revascularizations. In this study, we limited the assessment to only "in situ" ITAs and the LAD artery. For coronary revascularizations of the right coronary and left circumflex arteries, various types of grafts, such as those on the ITA, radial artery, gastro-epiploic artery, and saphenous vein, have been used in our institution. To distinguish the "in situ" graft from the aortocoronary graft, we studied only "in situ" ITA grafts to the LAD artery.

Third, characteristics affecting the quality of the "in situ" ITA graft, such as its diameter, calcification, and free flow, were not evaluated. The quality of the graft may have affected the graft flow. Fourth, MSCT was used mainly in postoperative graft assessment, and it can overestimate and underestimate coronary artery stenosis, compared with coronary angiography. We used MSCT in this study because evaluating asymptomatic patients with coronary angiography is difficult. Fifth, patients with both angina pectoris and old myocardial infarctions were included. Old myocardial infarctions can affect the vascular bed of the myocardium, thereby influencing graft flow.

\section{CONCLUSIONS}

In mild coronary artery stenosis evaluated via FFR, bypass graft flow competition is a possibility. The cutoff FFR value of 0.75 was not optimal, owing to graft flow competition.

\section{Conflict of Interest Statement}

Authors have nothing to disclose with regard to commercial support.

\section{References}

1. De Bruyne B, Fearon WF, Pijls NH, Barbato E, Tonino P, Piroth Z, et al Fractional flow reserve-guided PCI for stable coronary artery disease. $N$ Engl J Med. 2014;371:1208-17.

2. Pijls NHJ, van Schaardenburgh P, Manoharan G, Boersma E, Bech JW, van't Veer $\mathrm{M}$, et al. Percutaneous coronary intervention of functionally nonsignificant stenosis: 5-year follow-up of the DEFER Study. J Am Coll Cardiol. 2007;49: 2105-11.

3. Botman CJ, Schonberger J, Koolen S, Penn O, Botman H, Dib N, et al Does stenosis severity of native vessels influence bypass graft patency? A prospective fractional flow reserve-guided study. Ann Thorac Surg. 2007;83: 2093-7.

4. Seo MK, Koo BK, Kim JH, Shin DH, Yang HM, Park KW, et al. Comparison of hyperemic efficacy between central and peripheral venous adenosine infusion for fractional flow reserve measurement. Circ Cardiovasc Interv. 2012;5:401-5

5. De Bruyne B, Pijls NH, Barbato E, Bartunek J, Bech JW, Wijns W, et al. Intracoronary and intravenous adenosine $5^{\prime}$-triphosphate, adenosine, papaverine, and contrast medium to assess fractional flow reserve in humans. Circulation. 2003; 107:1877-83.

6. Task Force on Myocardial Revascularization of the European Society of Cardiology (ESC) and the European Association for Cardio-Thoracic Surgery (EACTS); European Association for Percutaneous Cardiovascular Interventions (EAPCI), Wijns W, Kolh P, Danchin N, Di Mario C, Falk V, Folliguet T, et al. Guidelines on myocardial revascularization. Eur Heart J. 2010:31:2501-55.

7. Kieser TM, Rose S, Kowalewski R, Belenkie I. Transit-time flow predicts outcomes in coronary artery bypass graft patients: a series of 1000 consecutive arterial grafts. Eur J Cardiothorac Surg. 2010;38:155-62. 
8. Leong DK, Ashok V, Nishkantha A, Shan YH, Sim EK. Transit-time flow measurement is essential in coronary artery bypass grafting. Ann Thorac Surg. 2005;79:854-77; discussion 857-8.

9. Giammarco Di, Pano M, Cirmeni S, Pelini P, Vitolla G, Di Mauro M Predictive value of intraoperative transit-time flow measurement for short-term graft patency in coronary surgery. J Thorac Cardiovasc Surg. 2006;132:468-74.

10. Tokuda Y, Song MH, Oshima H, Usui A, Ueda Y. Predicting midterm coronary artery bypass graft failure by intraoperative transit time flow measurement. Ann Thorac Surg. 2008;86:532-6.

11. D'Ancona G, Karamanoukian HL, Ricci M, Salerno TA, Bergsland J, eds. Intraoperative Graft Patency Verification in Cardiac and Vascular Surgery. Armonk, NY: Futura; 2001
12. Marshall MV, Rasmussen JC, Tan IC, Aldrich MB, Adams KE, Wang X, et al Near-infrared fluorescence imaging in humans with indocyanine green: a review and update. Open Surg Oncol J. 2010;2:12-25.

13. Rubens FD, Ruel M, Fremes SE. A new and simplified method for coronary and graft imaging during CABG. Heart Surg Forum. 2002;5: $141-4$.

14. Kitamura S, Kawachi K, Seki T, Sawabata N, Morita R, Kawata T. Angiographic demonstration of no-flow anatomical patency of internal thoracic-coronary artery bypass grafts. Ann Thorac Surg. 1992;53:156-9.

Key Words: FFR-guided coronary surgery, TTFM

Readers who found these articles interesting may also like to read the following papers found in recent and future issues of our sister publications, Seminars in Thoracic and Cardiovascular Surgery and Operative Techniques in Thoracic and Cardiovascular Surgery!

\section{Acquired Cardiovascular Disease: Coronary Artery Disease}

News and Views: Stephen Fremes. Outcomes of Arterial Revascularization. Semin Thorac Cardiovasc Surg. Autumn 2014;26(3): 174-175.

News and Views: Brian Buxton. Editorial on Multiple Arterial Grafting. Semin Thorac Cardiovasc Surg. Autumn 2014;26(3): 176-178.

News and Views: A. P. Kappetein. Role of PCI in the Treatment of Left Main Coronary Disease. Semin Thorac Cardiovasc Surg. Autumn 2014;26(3):187-191.

State of the Art: Victor Ferraris. Use of Anti-platelet Drugs after Cardiac Operations. Semin Thorac Cardiovasc Surg. Autumn 2014;26(3):223-230.

John Conte. Repair of Postinfarct Ventricular Septal Defect: Anterior Apical Ventricular Septal Defect. Oper Tech Thorac Cardiovasc Surg. Spring 2014;19(1):96-114.

Thomas Gleason. Repair of Postinfarction Ventricular Septal Defect: Posterior Inferior Ventricular Septal Defect. Oper Tech Thorac Cardiovasc Surg. Spring 2014;19(1):115-126. 